\title{
Similarities and Differences Between HFmrEF and HFpEF
}

\author{
Peixin $\mathrm{Li}^{1,2,3}$, Hengli Zhao ${ }^{1,2,3,4 \dagger}$, Jianyu Zhang ${ }^{5}$, Yunshan Ning ${ }^{4}$, Yan $\mathrm{Tu}^{1}$, Dingli $\mathrm{Xu}{ }^{1,2,3 *}$ and \\ Qingchun Zeng ${ }^{1,2,3 *}$ \\ ${ }^{1}$ State Key Laboratory of Organ Failure Research, Department of Cardiology, Nanfang Hospital, Southern Medical University, \\ Guangzhou, China, ${ }^{2}$ Guangdong Provincial Key Laboratory of Shock and Microcirculation, Southern Medical University, \\ Guangzhou, China, ${ }^{3}$ Bioland Laboratory (Guangzhou Regenerative Medicine and Health Guangdong Laboratory), \\ Guangzhou, China, ${ }^{4}$ School of Laboratory Medicine and Biotechnology, Southern Medical University, Guangzhou, China, \\ ${ }^{5}$ Department of Cardiology, Foshan First People's Hospital, Foshan, Guangdong, China
}

OPEN ACCESS

Edited by:

Koh Ono,

Kyoto University, Japan

Reviewed by:

Manuel Martínez-Sellés, Gregorio Marañón Hospital, Spain Yogesh Reddy,

Mayo Clinic, United States

${ }^{*}$ Correspondence: Qingchun Zeng

qingchunzeng@smu.edu.cn Dingli Xu

dlxugz@163.com

†These authors have contributed equally to this work

Specialty section

This article was submitted to Heart Failure and Transplantation,

a section of the journal

Frontiers in Cardiovascular Medicine

Received: 10 March 2021

Accepted: 23 July 2021

Published: 20 September 2021

Citation:

Li P, Zhao H, Zhang J, Ning Y, Tu Y, $X U D$ and Zeng Q (2021) Similarities and Differences Between HFmrEF and

HFPEF.

Front. Cardiovasc. Med. 8:678614.

doi: 10.3389/fcrm.2021.678614
The new guidelines classify heart failure (HF) into three subgroups based on the ejection fraction (EF): HF with reduced EF (HFrEF), HF with mid-range EF (HFmrEF), and HF with preserved EF (HFpEF). The new guidelines regarding the declaration of HFmrEF as a unique phenotype have achieved the goal of stimulating research on the basic characteristics, pathophysiology, and treatment of HF patients with a left ventricular EF of $40-49 \%$. Patients with HFmrEF have more often been described as an intermediate population between HFrEF and HFpEF patients; however, with regard to etiology and clinical indicators, they are more similar to the HFrEF population. Concerning clinical prognosis, they are closer to HFpEF because both populations have a good prognosis and quality of life. Meanwhile, growing evidence indicates that HFmrEF and HFpEF show heterogeneity in presentation and pathophysiology, and the emergence of this heterogeneity often plays a crucial role in the prognosis and treatment of the disease. To date, the exact mechanisms and effective treatment strategies of HFmrEF and HFpEF are still poorly understood, but some of the current evidence, from observational studies and post-hoc analyses of randomized controlled trials, have shown that patients with HFmrEF may benefit more from HFrEF treatment strategies, such as beta-blockers, angiotensin-converting enzyme inhibitors, angiotensin receptor blockers, mineralocorticoid receptor antagonists, and sacubitril/valsartan. This review summarizes available data from current clinical practice and mechanistic studies in terms of epidemiology, etiology, clinical indicators, mechanisms, and treatments to discuss the potential association between HFmrEF and HFpEF patients.

Keywords: heart failure, heart failure with mid-range ejection fraction, heart failure with preserved ejection fraction, heterogeneity, cardiac abnormality

\section{INTRODUCTION}

In 2016, heart failure (HF), a clinical syndrome with typical signs and symptoms triggered by a structural and/or functional cardiac abnormality resulting in reduced cardiac output (CO) and/or elevated intracardiac pressures at rest or during stress, was categorized into three subgroups based on left ventricular ejection fraction (LVEF): HF with reduced EF (HFrEF; EF < 40\%), HF with mid-range EF (HFmrEF; EF 40-49\%), and preserved EF (EF $\geq 50 \%$ ) (1). Compared with the previous guidelines, this new one identified HFmrEF as a unique phenotype that has 
been stimulating more research into the clinical characteristics, pathophysiology, and treatment of HFmrEF populations (2).

Data from the ESC Heart Failure Long-Term Registry showed that no significant difference was found in all-cause mortality between HFmrEF and HFrEF or HFpEF, while the mortality rate among HFrEF patients was markedly higher than that among HFpEF patients. Non-cardiovascular (CV) mortality was numerically higher in patients with HFmrEF and HFpEF than in those with HFrEF. The incidences of 1 -year death and hospitalization for $\mathrm{HF}$ among $\mathrm{HFmrEF}$ and $\mathrm{HFpEF}$ patients were less than those among $\mathrm{HFrEF}$ patients $(3,4)$. Additionally, in a pooled analysis of cohorts from three Northwestern European countries, patients with HFmrEF and HFpEF had similar survival rates, both of which were better than those for HFrEF patients $(4,5)$. In the APOLLON trial, an observational and multicenter study completed in Turkey $(6,7)$, the HFmrEF patients were more likely to have ECG abnormalities and a history of hospitalization due to HF in the last year, while a lower frequency of palpitations was observed in HFpEF patients.

Therefore, in this review, we briefly describe the existing knowledge on the epidemiology, etiology, and clinical indicators of HFpEF and HFmrEF and discuss the underlying mechanisms of these two subgroups. Finally, we present the evidence on current potential treatment options for these two groups of patients.

\section{EPIDEMIOLOGY}

In some registries and clinical trials, a significant proportion of patients with HF belong to the HFmrEF and HFpEF subgroups, with percentages ranging $8.1-24$ and $11-43 \%$, respectively (3-5, $8,9)$-for example, in the HF-PATHWAYS study in Spain, 19,762 patients with HF were identified out of $1,189,003$ patients treated from 2017 to 2019, and the distribution of LVEF was as follows: 51.7, 8.1, and 40.2\% were classified as having HFrEF, HFmrEF, and HFpEF, respectively (8). In the ESC HF Long-Term Registry, including all regions of European and Mediterranean countries, HFrEF, HFmrEF, and HFpEF accounted for 59.8, 24.2, and 16.0\%, of the cases, respectively, among 9,134 patients (3). Similarly, in a trial of 169 participating hospitals in China from 2017 to 2018, 11,034 (35.2\%) HFrEF patients, 6,825 (21.8\%) HFmrEF patients, and 13,497 (43.0\%) HFpEF patients were enrolled (5). In a Swedish registry, 4,942 patients were identified, $18 \%, 19 \%$, and $63 \%$ of whom had HFpEF, HFmrEF, and HFrEF, respectively (9). In another pooled analysis from the Northwestern European cohorts, 10,312 patients with stable HF were enrolled, including 7,080 (68.7\%) with HFrEF, 1,146 (11.1\%) with HFpEF, and 2,086 (20.2\%) with HFmrEF (4).

\section{ETIOLOGY}

Although patients with HFrEF and HFpEF share many similar risk factors (10), some comorbidities differ between them. The HFpEF patients are more likely to be older $(3,5)$, men are more likely to have HFrEF, and women are predisposed to HFpEF $(3,5,11)$. This can be attributed to women, compared with men, being more likely to suffer from the risk factors for HF, such as obesity, diabetes, mental/psychological stress, and socioeconomic deprivation (11). Additionally, men are more likely to have concentric hypertrophy, while women are more likely to suffer from eccentric hypertrophy (12). Patients with HFpEF have a higher comorbidity burden, including hypertension, atrial fibrillation/atrial flutter (AF), anemia, and chronic obstructive pulmonary disease (COPD) $(3,5)$ but are less likely to have ischemic etiology and left bundle branch block than HFrEF patients (3). Generally, patients with HFmrEF are more often described as an intermediate population between HFrEF and HFpEF patients. Nevertheless, the HFmrEF group resembled the HFrEF group with regard to age, sex, systolic blood pressure, and ischemic etiology but had less left ventricular (LV) and atrial dilation $(3,13)$; however, the most striking similarity between HFmrEF and HFrEF is that both are associated with a higher incidence of coronary artery disease and a greater risk of new ischemic heart disease than HFpEF (14). In addition, the HFmrEF and HFrEF populations had higher rates of previous myocardial infarction (MI) and AF than those with HFpEF $(7,13)$, whereas no significant differences were found in diabetes, chronic renal failure, or mean hemoglobin level between the HFmrEF and HFrEF groups (15). Additionally, regarding the history of hypertension, distribution of New York Heart Association class (NYHAC), and body mass index, the HFmrEF subgroup fell between the HFrEF and HFpEF groups (13) (Table 1).

\section{CLINICAL INDICATORS}

Higher laboratory parameters, including blood urea nitrogen, creatinine, N-terminal pro-B-type natriuretic peptide (NTproBNP), potassium, uric acid, and ferritin levels, were shown in populations of HFmrEF compared with HFpEF. Compared with the HFpEF patients, the HFmrEF patients had larger LV end-diastolic and end-systolic dimensions, a higher left atrial volume index and LV mass index, and a lower LVEF. Patients in the HFmrEF and HFpEF groups did not differ significantly in valvular disease (except for mitral regurgitation, from which the former group is more likely to suffer) or diastolic dysfunction parameters (6). A Swedish study assessed the association between NT-proBNP and CV vs. non-CV events in three subgroups of $\mathrm{HF}$ and found that the median NT-proBNP values in HFpEF and HFmrEF were similar but much lower than those in HFrEF. The occurrence of CV risk increased with lower EF values, while the occurrence of non- $\mathrm{CV}$ risk increased with higher EF values, and the $\mathrm{CV}$-nonCV event ratio was positively correlated with the NT-proBNP concentration (16). In a panel of 37 biomarkers from different pathophysiological domains [e.g., myocardial stretch, oxidative stress (OS), inflammation, angiogenesis, and hematopoiesis], HFrEF was most related to cardiac stretch, HFpEF to cardiac inflammation, and HFmrEF to both stretch and inflammation (17). Another study in Spain consisting of a series of biomarkers, including NT-proBNP, neprilysin, galectin-3, soluble suppression of tumorigenesis-2 (sST2), high-sensitivity troponin T (hs-TnT), cystatin-C, soluble 
TABLE 1 | Baseline characteristics of patients with HFmrEF and HFpEF.

\begin{tabular}{|c|c|c|c|c|c|c|c|c|c|c|}
\hline \multirow[t]{2}{*}{ Characteristics } & \multicolumn{2}{|c|}{ Chioncel et al. (3) } & \multicolumn{2}{|c|}{ Wang et al. (5) } & \multicolumn{2}{|c|}{ Tsuji et al. (14) } & \multicolumn{2}{|c|}{ Lund et al. (13) } & \multicolumn{2}{|c|}{ Moliner et al. (15) } \\
\hline & $n=2,212$ & $n=1,462$ & $n=6,825$ & $n=13,497$ & $n=596$ & $n=2,154$ & $n=1,322$ & $n=1,953$ & $n=134$ & $n=135$ \\
\hline Age (years) & $64.2 \pm 14.2$ & $68.6 \pm 13.7$ & $67.7 \pm 13.3$ & $71.3 \pm 12.5$ & $69.0 \pm 11.6$ & $71.7 \pm 10.9$ & $65 \pm 11$ & $67 \pm 11$ & $67 \pm 12$ & $69.6 \pm 14.4$ \\
\hline $\begin{array}{l}\text { Female gender } \\
\text { (\%) }\end{array}$ & 31.5 & 47.9 & 35.2 & 50.2 & 28.2 & 39.2 & 29.9 & 45.5 & 32.1 & 60.7 \\
\hline $\mathrm{SBP}(\mathrm{mmHg})$ & $126.5 \pm 21.1$ & $130.98 \pm 21.4$ & $131.3 \pm 22.4$ & $134.9 \pm 22.9$ & $124.7 \pm 19.3$ & $127.9 \pm 19.2$ & $130(120-145)$ & $\begin{array}{c}140 \\
(124-150)\end{array}$ & $132.4 \pm 20.6$ & $135.4 \pm 25.7$ \\
\hline $\begin{array}{l}\text { NYHA class } \\
\text { III-IV, } n(\%)\end{array}$ & 18.4 & 20.3 & 36.2 & 41.6 & 11.7 & 10.6 & 42.3 & 38.9 & 28.4 & 34.8 \\
\hline IHD (\%) & 41.8 & 23.7 & 60.8 & 57.1 & 52.9 & 44.1 & 66.9 & 50.4 & 54.5 & 13.3 \\
\hline DM (\%) & 30.5 & 29.3 & 30.7 & 28.5 & 36.1 & 33.8 & 28.6 & 28.1 & 29.9 & 37.8 \\
\hline $\mathrm{Ml}$ & & & 39.4 & 22.4 & 41.1 & 26.9 & 57.6 & 37.0 & & \\
\hline COPD (\%) & 11.6 & 14.0 & 7.4 & 9.6 & & & & & & \\
\hline $\begin{array}{l}\text { Prior stroke/TIA } \\
\text { (\%) }\end{array}$ & 8.3 & 9.8 & 14.6 & 17.5 & 22.1 & 21.9 & 9.3 & 8.4 & & \\
\hline $\begin{array}{l}\text { Chronic kidney } \\
\text { disease (\%) }\end{array}$ & 16.5 & 19.9 & 11.9 & 11.0 & & & & & & \\
\hline LBBB (\%) & 15.4 & 8.7 & 5.0 & 2.3 & & & & & & \\
\hline Anemia & & & 28.5 & 31.7 & & & & & & \\
\hline
\end{tabular}

$A F$, atrial fibrillation/flutter; BMI, body mass index; COPD, chronic pulmonary obstructive disease; DCM, dilated cardiomyopathy; DM, diabetes mellitus; IHD, ischemic heart disease; LBBB, left bundle branch block; MI, myocardial infarction; NYHA, New York Heart Association; SBP, systolic blood pressure; TIA, transient ischemic attack.

transferrin receptor (sTfR), and high-sensitivity C-reactive protein (hs-CRP), revealed that HFmrEF was quite similar to HFrEF because there were no differences in other measured biomarkers in HFmrEF and HFrEF, except that the level of NTproBNP was similar to that of HFpEF but was significantly decreased in HFrEF. When the HFmrEF patients were compared with the HFpEF patients, the HFmrEF patients had significantly lower levels of ST2 and cystatin C. The authors of the study also proposed that, except for galactose lectin-3 and neprilysin, all biomarkers of HFmrEF had a higher risk prediction ability than HFrEF or HFpEF, and only soluble neprilysin showed a superior prognostic value in patients with HFpEF than HFrEF and HFmrEF (15) (Table 2).

\section{UNDERLYING MECHANISMS OF HFPEF AND HFMREF}

Extensive data are lacking regarding the mechanism of HFmrEF. Therefore, we speculate on the underlying mechanism of HFmrEF, relying on current clinical registries and investigations that have reported the etiology and comorbidities of different EF values.
TABLE 2 | Clinical indicator of patients with HFmrEF and HFpEF.

\begin{tabular}{|c|c|c|c|c|c|c|}
\hline \multirow[t]{3}{*}{ Biomarkers } & \multicolumn{2}{|c|}{ Ozlek et al. (6) } & \multicolumn{2}{|c|}{ Moliner et al. (15) } & \multicolumn{2}{|c|}{ Tromp et al. (17) } \\
\hline & HFmrEF & HFpEF & HFmrEF & HFpEF & HFmrEF & HFpEF \\
\hline & $n=246$ & $n=819$ & $n=134$ & $n=135$ & $n=128$ & $n=108$ \\
\hline BUN & $\mathrm{H}^{*}$ & $L^{*}$ & NA & NA & L & $\mathrm{H}$ \\
\hline Creatinine & $\mathrm{H}^{*}$ & $L^{*}$ & NA & NA & NA & NA \\
\hline NT-proBNP & $\mathrm{H}^{*}$ & $L^{*}$ & $\mathrm{H}$ & L & $\mathrm{H}^{*}$ & $L^{*}$ \\
\hline Uric acid & $\mathrm{H}^{*}$ & $L^{*}$ & NA & NA & NA & NA \\
\hline Ferritin & $\mathrm{H}^{*}$ & $L^{*}$ & NA & NA & NA & NA \\
\hline Neprilysin & NA & NA & L & $\mathrm{H}$ & NA & NA \\
\hline Galectin-3 & NA & NA & L & $\mathrm{H}$ & L & $\mathrm{H}$ \\
\hline sST2 & NA & NA & $L^{*}$ & $\mathrm{H}^{*}$ & L & $\mathrm{H}$ \\
\hline hs-TnT & NA & NA & L & $\mathrm{H}$ & NA & NA \\
\hline sTfR & NA & NA & L & $\mathrm{H}$ & NA & NA \\
\hline hs-CRP & L & $\mathrm{H}$ & L & $\mathrm{H}$ & $L^{*}$ & $\mathrm{H}^{*}$ \\
\hline Cystatin C & NA & NA & $L^{*}$ & $\mathrm{H}^{*}$ & NA & NA \\
\hline
\end{tabular}

BUN, blood urea nitrogen; hs-CRP, high-sensitivity C-reactive protein; hs-TnT, highsensitivity troponin T; NT-proBNP, N-terminal pro-B-type natriuretic peptide; sTfR, soluble transferrin receptor; $S S T 2$, soluble suppression of tumorigenesis-2; $H$, higher $-P>0.05$; $L$, lower $-P>0.05 ; H^{*}$, higher $-P<0.05 ; L^{*}$, lower $-P<0.05$. 
However, numerous HFpEF mechanistic studies have been performed recently, including those on coronary microvascular dysfunction centered on inflammation and endothelial damage and energy production disturbance and myocardial metabolic abnormalities centered on mitochondrial injury as well as diastolic dysfunction related to myocardial fibrosis and calcium homeostasis disorder.

Therefore, in the following section, we discuss the underlying mechanism of HFmrEF and HFpEF from inflammation, cardiomyocyte injury, endothelial dysfunction, cardiac fibrosis, $\mathrm{Ca}^{2+}$ homeostasis, and mitochondrial dysfunction.

\section{Inflammation}

Since the new HFpEF paradigm of coronary microvascular inflammation was proposed in 2013, more preclinical and clinical data have emerged (18). The new paradigm in HFpEF results from a series of factors consisting of the following: (1) comorbidities, (2) reactive oxygen species, (3) limited NO bioavailability, (4) low protein kinase G (PKG) activity, and (5) diastolic dysfunction (19).

Extracardiac metabolic inflammation, such as overweight/obesity, diabetes, COPD, and hypertension, plays an important role in the pathogenesis of both HFpEF (19) and HFmrEF patients. In obese and type 1 and 2 diabetic patients, elevated levels of advanced glycation end products (AGEs) $(20,21)$ bind to their receptor, triggering the downstream $\mathrm{NF} \mathrm{B}$ signaling pathway and thereby promoting the secretion of adhesion molecules, chemokines, and proinflammatory cytokines (19); moreover, the concentrations of ST2 and cystatin-C were significantly higher in patients with $\mathrm{HFpEF}$ than in those with HFmrEF (15). However, tissue damage and necrosis (recognized as danger-associated molecular patterns, DAMPs) caused by ischemia, such as myocardial infarction, will lead to the release of cardiac antigens, which, in turn, induces local and systemic inflammatory responses (22) that are more common in HFmrEF. Simmonds et al. summarized this response as sterile inflammation induced by (a) exposure to host-derived non-microbial stimuli released through tissue injury and activation of the pathogen recognition receptor (PRR) pathway in a response called DAMPs, such as DNA, ATP, and hyaluronan, (b) activation of common pathways downstream of PRRs via released intracellular cytokines, and/or (c) activation of pathways unrelated to microbial recognition receptors, such as cluster of differentiation 36 (23-25).

These findings suggest that extracardiac metabolic inflammation may play a more important role in HFpEF, while sterile inflammation caused by ischemia appears more important in patients with HFmrEF.

\section{Endothelial Dysfunction}

Endothelial cells constitute the majority of non-cardiomyocytes (>60\%); their structural and/or functional abnormalities will strongly affect cardiac function, especially in HFpEF (26). Endothelial dysfunction is an early event in CV disease progression in HFpEF patients as opposed to the late-stage symptom that is often present in patients with HFrEF (19). Some complications, such as diabetes, can affect endothelial function to varying degrees, especially considering that the patients with HFpEF are more likely to suffer from metabolic complications, and the risk of endothelial dysfunction was more likely to be prevalent in patients with HFpEF than HFrEF (27). HFpEF myocardial biopsies confirmed this theory; compared with HFrEF patients, the bioavailability of NO decreased, and the uncoupling of eNOS increased (28). The imbalance of NO bioavailability and OS leads to the decreased endotheliumdependent vasodilatory function of coronary arteries (2931 ), resulting in reduced myocardial perfusion and impaired coronary blood flow (29). The reduced NO results in decreased activities of cyclic guanosine monophosphate (cGMP) and PKG and increased activities of protein phosphatase 1 and 2a (28). Downregulating NO-cGMP-PKG signaling may be attributed to cardiomyocyte hypertrophy and stiffness in HFpEF.

However, the role of endothelial dysfunction in the pathophysiology of HFmrEF has not yet been reported, and further study is needed. Another study demonstrated that the levels of endothelial dysfunction biomarkers (endothelin-1 and E-selectin) were interrelated with EF (32).

\section{Cardiomyocyte Injury}

In the pathophysiology of HFpEF, growing evidence shows that coronary microvascular dysfunction leads to cardiomyocyte injury, especially in women with cardiometabolic risk factors and LVH (18). In a research on multiple biomarkers in Spain, Moliner et al. showed that the TnT level, a typical biomarker reflecting cardiomyocyte injury, in HFmrEF patients was twofold higher than those in HFrEF and HFpEF patients (15). Combined with its ischemic etiology, it is plausible that cardiomyocyte injury, but not cardiomyocyte death, may play a greater role in patients with HFmrEF than HFpEF. Additionally, several studies have demonstrated elevations in troponin I (TnI) (33) and TnT (34) in patients with HFpEF. Obokata et al. (34) found that the TnT levels were elevated in HFpEF both at rest and during exercise, and the extent of the rise was directly related to the increase in left ventricular filling pressure due to the lower myocardial oxygen supply and the imbalance of myocardial oxygen supply-demand. These findings suggested that cardiomyocyte injury was involved in the development of both HFpEF and HFmrEF patients and may provide a novel therapeutic target for this syndrome.

\section{Diastolic Dysfunction Associated With Cardiac Fibrosis and $\mathrm{Ca}^{2+}$ Homeostasis}

Diastolic dysfunction, as a hallmark of HFpEF, is triggered by abnormalities in excitation-contraction coupling (35) and ventricular stiffness (36), while cardiac fibrosis and abnormalities in active relaxation and passive stiffness (F-passive) (37) mainly affect ventricular stiffness and, thus, decrease ventricular filling, elevating ventricular pressures during diastole (38) (Figure 1).

\section{Cardiac Fibrosis}

Myocardial fibrosis, as an important pathophysiological mechanism, plays a key role in the emergence and progression of the disease, regardless of EF (39). In patients with HFmrEF and HFpEF, myocardial fibrosis was demonstrated by cardiac magnetic resonance imaging $(\mathrm{CMR})$ and endomyocardial 


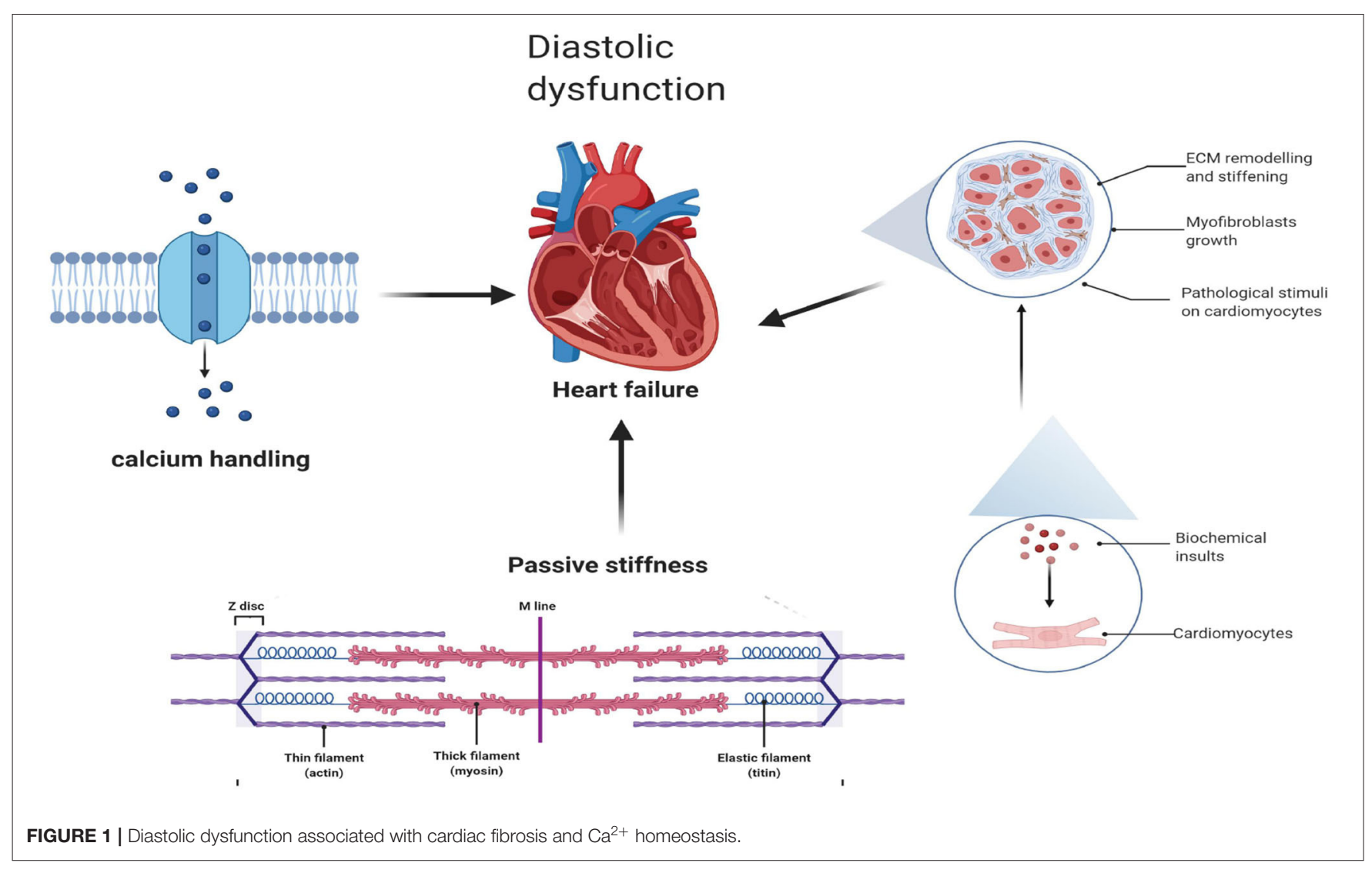

biopsies (40-42). It is interesting to note that CMR imaging of both $\mathrm{T} 1$ and $\mathrm{T} 2$ relaxation, reflecting the degree of cardiac fibrosis, was markedly increased in populations of HFmrEF, suggesting that populations of HFmrEF may share this pathophysiological mechanism (42).

Moreover, fibrosis-related biomarkers, including C-terminal propeptide of procollagen type I (PICP) and N-terminal propeptide of procollagen type III (PIIINP), which are regarded as biomarkers of type I and III collagen formation, respectively (43), were significantly higher in the HFmrEF group than in the HFpEF group (44). In a healthy heart, the extracellular matrix (ECM) is mainly composed of collagen with thicker type I collagen fibers $(\sim 85-90 \%$ of total collagen $)$ and thinner type III collagen fibers ( $\sim-11 \%)$ (45). Among them, type I collagen fibers mediate tensile strength, while type III collagen fibers maintain the elasticity of the matrix network (45). In patients with HFmrEF, the PICP and PICP/PIIINP ratios were higher than those in HFpEF patients. This may indicate that there is an equilibrium transfer to type I collagen synthesis in cardiac fibrosis among HFmrEF patients (44), while in HFpEF patients excessive collagen deposition and a shift in collagen type proportion, predominantly a reduction in collagen III, result in increased cardiac stiffness (46).

\section{Passive Stiffness}

Ventricular stiffness is not only caused by cardiac fibrosis (as described above) but also related to abnormal active relaxation and passive stiffness (F-passive) (37). Titin, a large sarcomeric protein extending from the $\mathrm{Z}$ disk to the $\mathrm{M}$-line and encoded by a single gene (47), is the main determinant of $F$ passivity in cardiomyocytes. Different splicing results in different sizes of $\mathrm{N} 2 \mathrm{~B}$ and N2BA subtypes in the myocardium. Small mammals mainly express $\mathrm{N} 2 \mathrm{~B}$ titers, while large mammals, including humans, express both stiffer N2B and more flexible N2BA titers (48). Animal models of HFpEF show a shift from N2BA to $\mathrm{N} 2 \mathrm{~B}$, which is related to the F-passive increase (49). In contrast, in cardiac biopsies from patients with HFrEF, N2BA subtypes were increased, with no change in total titin levels, indicating a reduction in F-passivity as a result of the transfer from N2B to N2BA subtypes (47).

\section{Excitation-Contraction Coupling and Calcium Handling}

Excitation-contraction coupling in the heart is a process in which cardiomyocytes are switched from electrical excitation to mechanical force (excitation-contraction). As an indispensable regulator of ECG activity, $\mathrm{Ca}^{2+}$ is directly involved in the process of contraction and relaxation of cardiomyocytes. $\mathrm{Ca}^{2+}$ released from the sarcoplasmic reticulum (50) acts as a direct activator of myofilaments and will cause cardiac contraction (51). Cardiac relaxation, as a key player in the pathophysiology of HFpEF (52), depends on the reduction of intracellular calcium $\left(\mathrm{Ca}^{2+}\right)$ levels (24), which can be reduced by (1) SERCA, (2) sarcolemmal $\mathrm{Na}+/ \mathrm{Ca}^{2+}$ exchange, (3) sarcolemmal 


\section{Exercise intolerance}
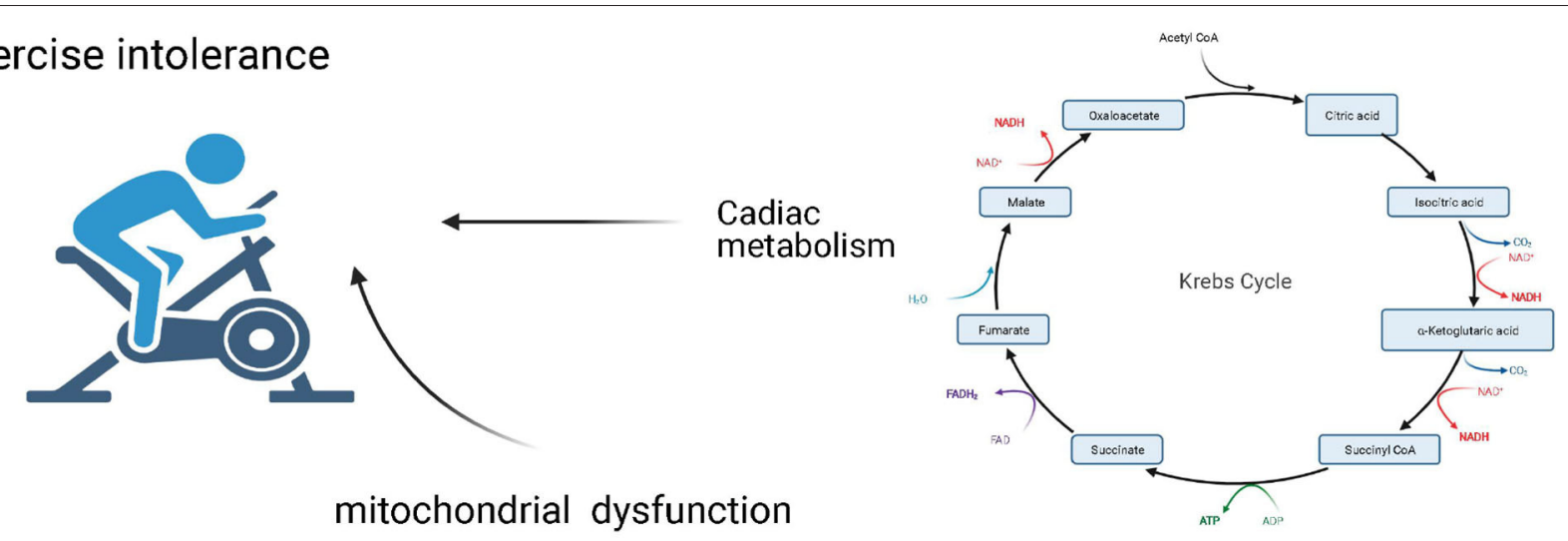

mitochondrial dysfunction

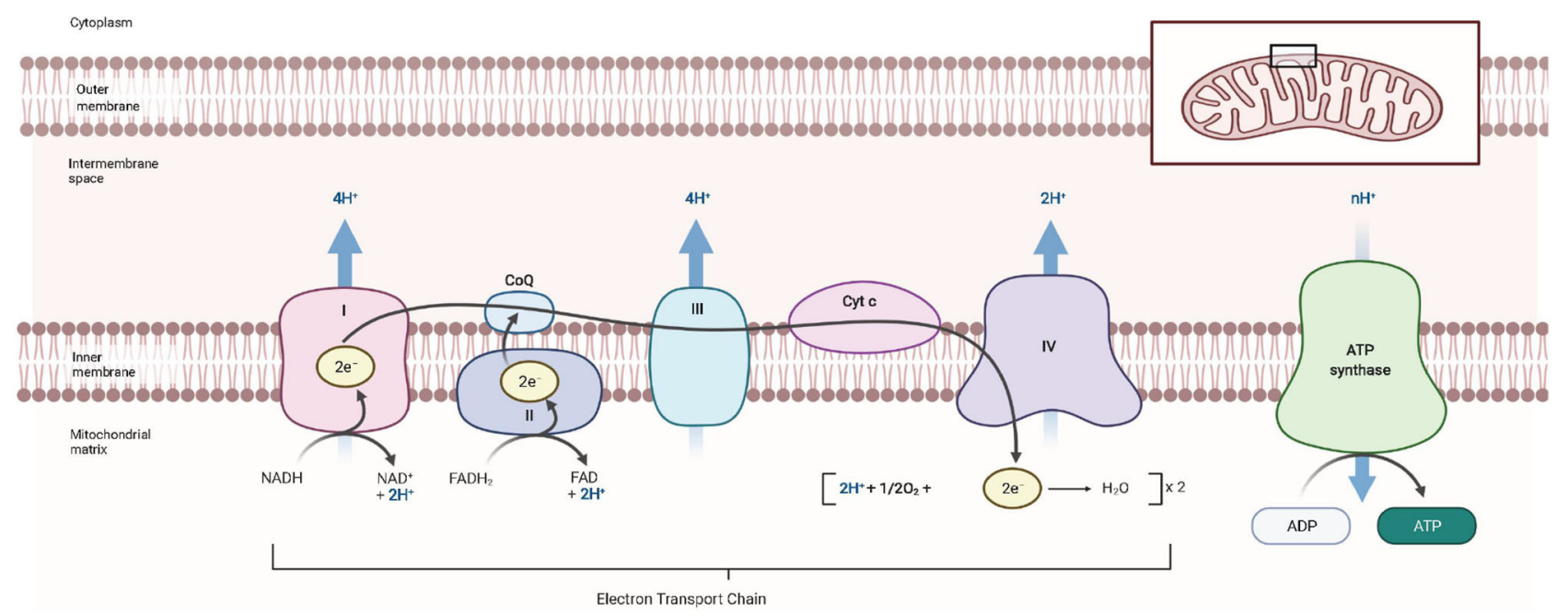

FIGURE 2 | Exercise intolerance associated with mitochondrial dysfunction and cardiac metabolism.

$\mathrm{Ca}^{2+}$-ATPase, and (4) mitochondrial $\mathrm{Ca}^{2+}$ UniProt $(51,52)$. Myocardial $\mathrm{Ca}^{2+}$ levels are increased in patients with $\mathrm{HFpEF}$, but elevated calcium levels (53) are not associated with an impaired $\mathrm{Na}+$ gradient, in contrast to the case in HFrEF patients who have elevated myocardial $[\mathrm{Na}+] \mathrm{I}$ (54). The mitochondria also participate in the process of $\mathrm{Ca}^{2+}$ concentration regulation because of their capacity to take up cytosolic $\mathrm{Ca}^{2+}\left(\left[\mathrm{Ca}^{2+}\right] \mathrm{c}\right)$ and then use it to regulate energy metabolism, such as in ATP regeneration (55). In rat models of HFpEF cardiomyocytes, free mitochondrial calcium concentrations were higher due to changes in cytosolic and mitochondrial $\mathrm{Ca}^{2+}$ processing. In the case of mild mitochondrial dysfunction, the coupling of cytosolic and mitochondrial $\mathrm{Ca}^{2+}$ levels may compensate for the myocardial ATP supply (56).

\section{Exercise Intolerance Associated With Mitochondrial Dysfunction and Cardiac Metabolism}

Exercise intolerance is common in the HFpEF population (57) and may be caused by an imbalanced systemic coordination between the cardiac pump, respiratory system, and arterial system (58). Inhaled oxygen will be delivered to the mitochondria of the skeletal muscle and the myocardium, where it can be used to generate ATP to maintain cardiac contraction and relaxation (Figure 2).

\section{Mitochondrial Dysfunction}

Under normoxic conditions, more than 95\% of ATP in the heart is produced by the oxidative phosphorylation of the mitochondria (59), suggesting the vital role this organelle plays in energy production. The structural and functional alterations in this organelle result in an insufficient energy supply in HF patients. Mitochondrial energy production, consisting of the coupling between electron transfer and oxygen uptake, occurs through electron transport chain (ETC) complexes and the phosphorylation of ADP to ATP by F0F1-ATP synthase, also known as complex V (60). A study conducted by Haykowsky et al. demonstrated that, in HFpEF patients, exercise time, peak power output, $\mathrm{CO}$, arterial-venous oxygen difference $\left(\mathrm{A}-\mathrm{VO}_{2}\right.$ diff), and peak exercise oxygen consumption (peak $\mathrm{VO}_{2}$ ), a widely validated measure of exercise capacity, were all significantly reduced (61). These findings may suggest a dysfunction between the oxygen delivery and utilization systems. Early theories posited that exercise intolerance and reduced 
$\mathrm{VO}_{2}$ were primarily caused by the absence of a corresponding increase in $\mathrm{CO}(62,63)$. However, recently, more researchers have attributed this discrepancy to peripheral abnormalities (61, 64-66). Among these abnormalities, dysfunction in skeletal muscle mitochondria or cardiomyocyte mitochondria or both appears to be an important pathophysiological contributor (63). Compared with the HFrEF patients, the peak value of $\mathrm{A}-\mathrm{VO}_{2}$ diff in HFpEF and HFmrEF patients was significantly lower (67), and another trial, conducted by Bhella et al. (64), showed that, in well-compensated HFpEF patients, the cardiac reserve indices were not impaired. $\mathrm{A}-\mathrm{VO}_{2}$ diff at rest was greater in HFpEF patients than in healthy controls, and exercise training significantly improved the cardiorespiratory fitness in patients with HFpEF. These findings may suggest exercise intolerance in HFmrEF and HFpEF patients predominantly due to peripheral factors, unlike HFrEF, which is caused by impaired cardiac pump performance (67).

The mechanisms of mitochondrial dysfunction are varied $(52,68)$ and include (i) low activity of the ETC complex $(69,70)$, (ii) defects in the supermolecular assembly of ETC complexes (71), (iii) increased OS (72), (iv) altered mitochondrial inner membrane (tetralinoleoyl cardiolipin), (v) changes in the tricarboxylic acid cycle (73), (vi) mitochondrial uncoupling (74), (vii) altered energy substrate availability (75), and (viii) abnormal quality control of mitochondrial fission and fusion (76).

\section{Cardiac Metabolism}

Cardiac metabolism comprises numerous biochemical processes that result in the conversion of substrates for generating energy to meet cell function, growth, and contraction needs. However, due to changes in oxidative substrate utilization and damaged mitochondrial oxidative metabolism, HF patients may exhibit energy deficiency (the ATP levels in HF patients decreased by $30-40 \%$ compared with those in healthy hearts) (77).

In Dahl-sensitive rats fed a high-salt diet, changes in energy metabolism during the early stage of HFpEF mainly include an increase in glycolysis, but the increased glycolysis is not accompanied by an increase in glucose oxidation, suggesting that glycolysis and glucose oxidation are decoupled. The fatty acid oxidation rates were in a state of progressive decrease following the high-salt diet (78).

In HFpEF patients, fatty acid oxidation is increased and glucose oxidation is decreased; moreover, there is a state of uncoupling between glucose uptake and glucose oxidation, leading to an increased rate of glycolysis (75). Choi et al. demonstrated that decreased cardiac fatty acid oxidation led to the development of diastolic dysfunction and that targeting acetyl-CoA carboxylase 2, which is a mitochondrial protein directed by its hydrophobic N-terminal leader sequence in the mitochondrial membrane as an essential rate-limiting enzyme in fatty acid metabolism (79), has a positive effect on sustaining mitochondrial fatty acid oxidation, protecting against pathological remodeling, maintaining mitochondrial function, and preventing increases in OS in mice subjected to ATII infusion (80).

Ketone bodies, consisting of $\beta$-hydroxybutyrate ( $\beta$-OHB), acetoacetate, and acetone, are produced predominantly in the liver from FAO-derived acetyl-coenzyme A (CoA) and are transported to extrahepatic tissues for terminal oxidation (81). Alternations in the circulating level of ketone bodies have been shown in HF, which the failing heart relies more on glycolysis and ketone body oxidation (82) as an energy source. This phenomenon has been verified in an HFrEF mouse model, and increased ketone utilization in advanced HF patients was observed $(83,84)$. Ketone bodies may play a role by inducing adipocytes to uptake fatty acids in the circulation and stimulating cardiomyocytes to uptake glucose, which, in turn, alters the oxidative substrate supply and improves cardiac energy production (85). This is in accordance with a recent study performed by Deng et al. that suggested that increasing myocardial ketone utilization ( $\beta$-OHB abundance) could significantly mitigate HFpEF phenotypes (86). The mechanism of this improvement was to reduce the acetylCoA pool by inhibiting fatty acid uptake and increasing citrate synthase activity to terminate the vicious cycle of mitochondrial dysfunction and inflammation.

\section{THERAPIES FOR HFMREF AND HFPEF}

The current ESC guidelines recommend therapies for HFmrEF based on the evidence for HFpEF rather than that for HFrEF. However, in actual clinical practice, the treatment of HFmrEF is closer to that of HFrEF (Table 3).

\section{Beta-Blockers}

The results of a meta-analysis consisting of 11 clinical trials showed that beta-blockers may halve CV mortality, particularly in the $40-50 \%$ LVEF subgroup ( $p=0.040$ ), regardless of ischemic or non-ischemic etiology. Despite the small number of events, its benefits were similar to those observed in HFrEF, with reductions in both HF-related death and sudden death (89). It is worth noting that the "HFmrEF patients" in the Cleland study accounted for $<4 \%$ of the entire study population, and the LVEF of most HFmrEF patients was $<43 \%$ (median value, $40 \%)(89,90)$. Consistent with the above-mentioned findings, the CHART-2 study revealed that, among patients with chronic HF, beta-blockers were related to improved mortality in patients with HFmrEF and HFrEF ( $p=0.010$ and $p=0.008$, respectively), while there was no significant difference in HFpEF patients (14). Overall, most evidence $(14,89,91)$ shows potentially positive effects on short- and long-term outcomes in patients with HFmrEF (92). For HFpEF patients, evidence for the routine use of beta-blockers is inconsistent (93), so the current guidelines do not favor the use of beta-blockers as a general treatment in the HFpEF population (94).

\section{ACEls and ARBs}

The current guidelines recommend treatment of HFmrEF closer to that of HFpEF compared with HFrEF (95). However, in the 2019 update of the Clinical Practice Expert Consensus Report, it was suggested that candesartan may be considered for HFmrEF patients with symptoms to reduce their risk of heart failure hospitalization and CV death (96). 
TABLE 3 | Common treatment of patients with HFmrEF and HFpEF.

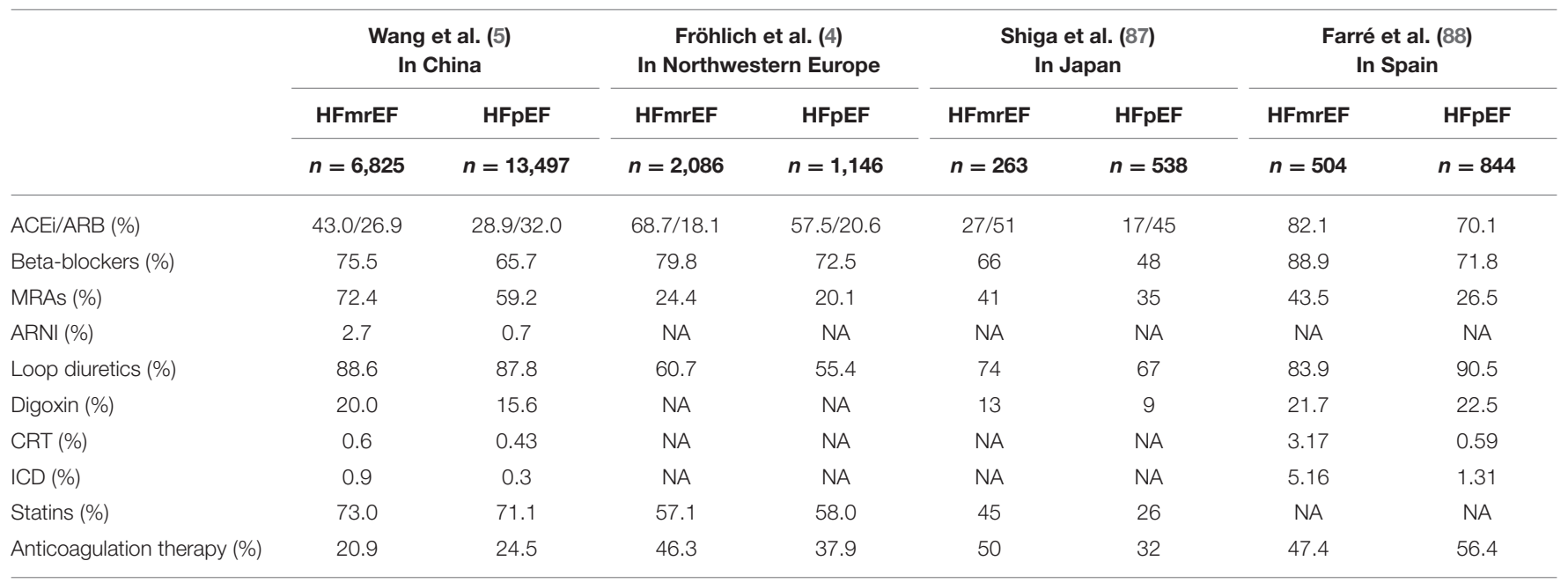

ACEl, ACE inhibitor; ARB, angiotensin II receptor blocker; ARNI, angiotensin receptor enkephalinase inhibitor; CRT, cardiac resynchronisation therapy; HFmrEF, heart failure with mid-range

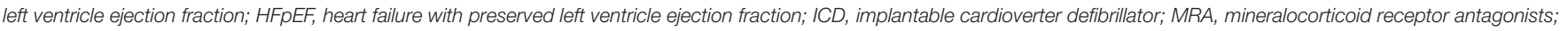
NA, not available.

In the CHARM data, the populations of HFmrEF and HFpEF accounted for $17 \%(n=1,322)$ and $26 \%(n=1,322)$ of the study patients, respectively (13). Candesartan significantly reduced the primary composite outcome, namely, first HF hospitalization and recurrent HF hospitalization in HFmrEF patients, whereas in HFpEF patients, it did not significantly reduce any outcome. These findings suggest that candesartan improves the outcomes in HFmrEF patients, except that the EF is over 50\% (13). Other data from the Swedish HF registry, which identified 42,061 patients, among whom $21 \%$ had HFmrEF and $23 \%$ had HFpEF, revealed that ACEIs/ARBs are effective in both HFmrEF and HFpEF patients with or without coronary heart disease (97).

In the Hong Kong Diastolic Heart Failure Study (98), the ARB irbesartan and ACEI ramipril did not demonstrate a significant alleviation of the symptoms of HFpEF patients. Another study on irbesartan performed by Massie et al. reached the same conclusion (99). Therefore, neither ACEI nor ARB treatment is recommended in the current guidelines for patients with $\operatorname{HFpEF}(2)$.

\section{Mineralocorticoid Receptor Antagonists}

A recent meta-analysis of randomized clinical trials was conducted to explore the efficacy and the safety of spironolactone in the HFmrEF and HFpEF populations. They selected 4,539 patients from 11 randomized controlled trials and concluded that spironolactone treatment may have beneficial effects for HFmrEF and HFrEF patients, namely, reducing hospitalizations and BNP levels, improving NYHA functional classifications (NYHA-FC), and alleviating myocardial fibrosis. Additionally, the only side effects of spironolactone that are of concern are hyperkalemia and gynecomastia (100). The greatest potential benefit from spironolactone treatment has been shown in patients with HFmrEF $(45 \% \leq \mathrm{LVEF}<50 \%)$ compared with other subgroups (LVEF $\geq 50 \%$ ), especially for those patients with LVEF $>65 \%$ and who experienced few positive effects, according to a TOPCAT trial that enrolled patients with HFpEF (LVEF $\geq 45 \%)$ (101). They also reported that spironolactone therapy appears to be effective in patients with lower LVEF (LVEF $<50 \%$ ) in reducing HFH and the primary endpoint (101). In accordance with these conclusions, the Japanese Cardiac Registry of Heart Failure in Cardiology reported that, at a mean follow-up of 2.2 years, spironolactone significantly reduced the compound mortality of all-cause death or heart failure rehospitalization (102). Another retrospective study from China came to the same conclusion, namely, spironolactone markedly reduced rehospitalization and the incidence of the primary composite outcome of all-cause death in HFmrEF patients (103). Meanwhile, research that limited the TOPCAT analysis to patients in the Americas, consisting of 1,644 HFpEF patients, showed that, compared with placebo, spironolactone treatment markedly reduced the clinical symptoms of congestion, and lower congestion was independently associated with a higher quality of life and better outcomes (104).

\section{Sacubitril/Valsartan}

Sacubitril/valsartan has shown better effects in reducing the risks of death and hospitalization in patients with HFrEF than enalapril (105), but whether it has similarly beneficial effects in HFmrEF and HFpEF populations is still unclear. Therefore, following the PARADIGM-HF trial in HFrEF patients (105), the 2019 PARAGON trial screened 4,796 patients with LVEF $\geq 45 \%$ and symptomatic HF, accompanied by elevated levels of natriuretic peptides and cardiac structural abnormalities, and then assessed the clinical outcomes of patients treated with sacubitril-valsartan or valsartan (106). During a median follow-up of 35 months, Solomon et al. found that there was no significant benefit of sacubitril/valsartan on the primary composite outcome of the total hospitalization for HF and death from CV causes. However, among one of the prespecified subgroup analyses, those with LVEF in the lower 
part $(45-57 \%)$ of the range were more likely to benefit from sacubitril/valsartan. The rates observed in the subgroup below the median were similar to those observed in the PARADIGMHF trial, which was focused on the HFrEF population (106). Meanwhile, patients treated with sacubitril/valsartan were more likely to suffer hypotension but less likely to have elevated creatinine and potassium concentrations compared with those in the valsartan-alone group. A recent meta-analysis of a total of 5,503 patients from six studies reported that sacubitrilvalsartan may play an effective and safe role in improving the clinical symptoms and reducing $\mathrm{HFH}$ in HFmrEF and HFpEF patients (107).

\section{Statins}

Statins have been shown to reduce the morbidity and the mortality in CVD and other related diseases, such as MI, stroke, and revascularization (108-110), but their effectiveness in HFmrEF and HFpEF is still inconclusive. An observational study from the Swedish Heart Failure Registry performed by Alehagen et al. proposed a possible benefit of statins in reducing all-cause mortality and CV hospitalization in patients with HFmrEF and HFpEF. Meanwhile, statins had a positive effect in controlling mortality and the combined endpoint of all-cause mortality (111).

\section{Sodium-Glucose Cotransport Protein 2 Inhibitor}

The 2019 Clinical Practice Expert Consensus Report proposed that sodium-glucose cotransport protein 2 (SGLT2) inhibitors (canagliflozin and dapagliflozin) may be considered for patients with T2DM and those with CV disease or high CV risks to prevent or delay the onset of hospitalizations associated with $\mathrm{HF}$ (96). SGLT2 inhibitors can maintain electrophysiological stability (cardiomyocyte $\mathrm{Na}+/ \mathrm{H}$ exchanger inhibition) (112) and cardiac hemodynamics (113), inhibit cardiac fibrosis (114), and improve myocardial systolic and diastolic function (115). Thus, in theory, more HFpEF patients could benefit from SGLT2 inhibitors. In the EMPA-REG OUTCOME ${ }^{\circledR}$ trial, patients with T2DM were at a high risk of $\mathrm{CV}$ events, and empagliflozin was associated with a $38 \%$ decrease in CV-related death, a $35 \%$ reduction in HF hospitalization, and a $32 \%$ reduction in all-cause mortality (116). In a post-hoc analysis of DECLARE-TIMI 58, among HFrEF populations who had a pre-specified EF cutoff point of $<45 \%$, including the population that is now defined as HFmrEF with an ejection fraction of 40-49\%, dapagliflozin showed a greater benefit in HF hospitalization and CV death than patients with an EF known to be $\geq 45 \%$ or those without EF history. Furthermore, a similar reduction in HF hospitalization was found in patients with $\mathrm{HF}$ regardless of EF, but a greater reduction with dapagliflozin in CV death was only found in HFrEF patients (117). Although some animal experiments have demonstrated the efficacy of SGLT2 inhibitors in HFpEF models, including improving cardiac diastolic function (118), cardiac hypertrophy, and tissue fibrosis $(119,120)$, there is still insufficient evidence to extend these studies to clinical practice in HFpEF or even HFmrEF patients.

\section{Vericiguat}

In HFpEF, the intracellular NO-cGMP-PKG signal cascade is disturbed (121), and downregulating NO-cGMP-PKG signaling may be attributed to cardiomyocyte hypertrophy and stiffness in HFpEF. Vericiguat, as a soluble guanylate cyclase (SGC) stimulator, enables the direct generation of cGMP and maintains the sensitivity of SGC to endogenous NO (122), which may have a positive effect on the HFpEF population. In the phase 2 SOCRATES-PRESERVED study, vericiguat, at a study dose of 1.25/2.5/5/10 mg for 12 weeks in HFpEF (LVEF $\geq 45 \%$ ) patients, did not reduce the primary endpoint of NT-proBNP and left atrial volume levels compared with the placebo; however, the quality of life of HFpEF patients, as assessed by the Kansas City Cardiomyopathy Questionnaire (KCCQ), was improved after receiving the two higher doses of vericiguat, and the tolerability of vericiguat was also confirmed (123). Another study published in 2020 showed that, in patients with HFpEF (LVEF $\geq 45 \%$ ), vericiguat (15 and $10 \mathrm{mg} /$ day) did not significantly improve the KCCQ Physiological Limits Score or the 6-min walking distance (6MWD) after 24 weeks of treatment (124). The subjects (HFpEF patients) in both of the studies described above included a portion of the population that is now defined as HFmrEF (EFs 40-49\%). The hypothesis cannot be confirmed for this recent trial, possibly due to the following: (a) compared with the former trail, the subjects in a recent study had higher baseline KCCQ scores, a higher percentage of NYHAC II patients, and a lower proportion of NYHAC III patients, (b) the placebo group showed a higher improvement score than the former group, and (c) NO may not be a key regulatory factor in HFpEF progression. The phase 3 VICTORIA trial (125) investigated the efficacy of vericiguat in patients with $\mathrm{HFrEF}$ (LVEF $\leq 45 \%$ ). Studies have shown that vericiguat reduces the incidence of death from $\mathrm{CV}$ causes or hospitalization for HF, but it does not appear to be effective in patients with LVEF of $40-45 \%(125,126)$. This suggests that vericiguat may be more effective in patients at a high risk of $\mathrm{HF}$ decompensation.

\section{Cardiac Contractility Modulation}

Cardiac systolic modulation (CCM) is administered through an implantable pulse generator. It can enhance the contractility of the right ventricle by transmitting the CCM pulse to the right ventricle during the absolute refractory period (127). The 2019 expert consensus suggested that CCM may be considered for patients with HFrEF (LVEF 25-45\%) and a narrow QRS complex (<130 ms) (96).

CCM has been shown to improve the quality of life, LVEF, and NYHAC (115) during a 24-month follow-up performed by Muller et al. (128). This is consistent with a study performed by $\mathrm{Yu}$ et al., who indicated that CCM improved both global and regional LV contractility, which may contribute to the reversal of LV remodeling and improved systolic function as well as improved performance in the 6MWD and NYHA-FC (129). These findings have recently been supported by another randomized FiX-HF 5C trial (130), including a total of 160 patients with NYHA-FC symptoms, QRS duration $<130 \mathrm{~ms}$, and $\mathrm{LVEF} \geq 25$ and $\leq 45 \%$. It showed increases in peak oxygen uptake as well as in Minnesota Living With Heart 
Failure Questionnaire $(P<0.001)$, NYHAC $(P<0.001)$, and 6MWD $(P=0.02)$ scores. This study further confirmed that, in the affected population, cases with an EF between 35 and $45 \%$, including some cases of HFmrEF (EFs 40-49\%), gain greater clinical benefits than those with $\mathrm{EF}<35 \%$ (130). These findings show that CCM may be considered for HF patients with higher EFs, especially for those with pathogenesis that includes $\mathrm{Ca}^{2+}$ processing, cytoskeletal stability, changes in ECM, and excessive activation of the autonomic nervous system (131), all of which are related to the pathophysiological mechanism of HFpEF (132).

\section{CONCLUSIONS}

The emergence of the concept of HFmrEF has achieved its aim to draw increasing attention from researchers on its mechanism, treatments, and clinical characteristics. However, considering current evidence and pathophysiology, the effective therapeutics for both HFmrEF and HFpEF patients are still insufficient, especially in the former. Compared with the HFpEF patients, the HFmrEF patients are more similar to HFrEF patients with respect to clinical characteristics, such as age, sex, systolic blood pressure, and ischemic etiology as well as clinical biomarkers such as hs-TnT and hs-CRP. The pharmacological treatment in HFmrEF has also followed almost the same strategies as those in HFrEF. However, with regard to the clinical prognosis and some aspects of the pathophysiology mechanism, HFmrEF and HFpEF share some commonalities. A recent study also demonstrated that

\section{REFERENCES}

1. Ponikowski P, Voors AA, Anker SD, Bueno H, Cleland J, Coats A, et al. 2016 ESC Guidelines for the diagnosis and treatment of acute and chronic heart failure: the task force for the diagnosis and treatment of acute and chronic heart failure of the European society of cardiology (ESC) Developed with the special contribution of the heart failure association (HFA) of the ESC. Eur Heart J. (2016) 37:2129-200. doi: 10.1093/eurheartj/ehw128

2. Ponikowski P, Voors AA, Anker SD, Bueno H, Cleland JG, Coats AJ, et al. 2016 ESC Guidelines for the diagnosis and treatment of acute and chronic heart failure: the task force for the diagnosis and treatment of acute and chronic heart failure of the European Society of Cardiology (ESC). Developed with the special contribution of the heart failure association (HFA) of the ESC. Eur J Heart Fail. (2016) 18:891-975. doi: 10.1002/ejhf.592

3. Chioncel O, Lainscak M, Seferovic PM, Anker SD, Crespo-Leiro MG, Harjola VP, et al. Epidemiology and one-year outcomes in patients with chronic heart failure and preserved, mid-range and reduced ejection fraction: an analysis of the ESC heart failure long-term registry. Eur J Heart Fail. (2017) 19:1574-85. doi: 10.1002/ejhf.813

4. Frohlich H, Rosenfeld N, Tager T, Goode K, Kazmi S, Hole T, et al. Epidemiology and long-term outcome in outpatients with chronic heart failure in Northwestern Europe. Heart. (2019) 105:1252-9. doi: 10.1136/heartjnl-2018-314256

5. Wang H, Li YY, Chai K, Zhang W, Li XL, Dong YG, et al. Contemporary epidemiology and treatment of hospitalized heart failure patients in real clinical practice in China. Zhonghua Xin Xue Guan Bing Za Zhi. (2019) 47:865-74. doi: 10.3760/cma.j.issn.0253-3758.2019.11.004

6. Ozlek B, Ozlek E, Agus HZ, Tekinalp M, Kahraman S, Cil C, et al. Patients with HFpEF and HFmrEF have different clinical characteristics in Turkey: a multicenter observational study. Eur J Intern Med. (2019) 61:88-95. doi: 10.1016/j.ejim.2018.11.001 patients whose LVEF deteriorated or improved to or remained stable at mid-range levels show a different prognosis, and patients with HFmrEF can even convert into HFpEF or HFrEF. Therefore, whether HFmrEF is an intermediate status, what the interaction is between HFmrEF and HFpEF or HFrEF, what the exact mechanism of HFmrEF is, and how this mechanism affects prognosis still warrant further study and exploration to improve the outcome in HFmrEF patients.

\section{AUTHOR CONTRIBUTIONS}

HZ, YN, YT, DX, and QZ contributed to the review design. PL, $\mathrm{HZ}$, and $\mathrm{JZ}$ searched and collected the relative literature. PL, $\mathrm{HZ}, \mathrm{YN}$, and QZ draw the manuscript. PL, HZ, JZ, YN, YT, DX, and QZ revised and finalized the manuscript. All authors contributed to manuscript revision, read, and approved the submitted version.

\section{FUNDING}

This project was partly supported by the Science and Technology Program of Guangzhou (201804010086 and 201707020012; QZ and DX), the National Natural Science Foundation of China (82070403 and 81770386; QZ), the Frontier Research Program of Guangzhou Regenerative Medicine and Health Guangdong Laboratory (2018GZR110105001; QZ), and the Youth Science and Technology Innovation Talent of Guangdong TeZhi Plan (2019TQ05Y136; QZ).
7. Vedin O, Lam C, Koh AS, Benson L, Teng T, Tay WT, et al. Significance of ischemic heart disease in patients with heart failure and preserved, midrange, and reduced ejection fraction: a nationwide cohort study. Circ Heart Fail. (2017) 10:e003875. doi: 10.1161/CIRCHEARTFAILURE.117.0 03875

8. Sicras-Mainar A, Sicras-Navarro A, Palacios B, Varela L, Delgado JF. Epidemiology and treatment of heart failure in Spain: the HF-PATHWAYS study. Rev Esp Cardiol. (2020). doi: 10.1016/j.rec.2020.09.033. [Epub ahead of print].

9. Savarese G, Vedin O, D’Amario D, Uijl A, Dahlstrom U, Rosano G, et al. Prevalence and prognostic implications of longitudinal ejection fraction change in heart failure. JACC Heart Fail. (2019) 7:306-17. doi: 10.1016/j.jchf.2018.11.019

10. Vossschulte K. Specialization and the trend towards professional independence in medicine from a historical viewpoint. Munch Med Wochenschr. (1966) 108:793-7.

11. Lam C, Arnott C, Beale AL, Chandramouli C, Hilfiker-Kleiner D, Kaye DM, et al. Sex differences in heart failure. Eur Heart J. (2019) 40:3859-68. doi: 10.1093/eurheartj/ehz835

12. Krumholz HM, Larson M, Levy D. Sex differences in cardiac adaptation to isolated systolic hypertension. Am J Cardiol. (1993) 72:310-3. doi: 10.1016/0002-9149(93)90678-6

13. Lund LH, Claggett B, Liu J, Lam CS, Jhund PS, Rosano GM, et al. Heart failure with mid-range ejection fraction in CHARM: characteristics, outcomes and effect of candesartan across the entire ejection fraction spectrum. Eur J Heart Fail. (2018) 20:1230-9. doi: 10.1002/ ejhf.1149

14. Tsuji K, Sakata Y, Nochioka K, Miura M, Yamauchi T, Onose T, et al. Characterization of heart failure patients with mid-range left ventricular ejection fraction-a report from the CHART-2 study. Eur J Heart Fail. (2017) 19:1258-69. doi: 10.1002/ejhf.807 
15. Moliner P, Lupon J, Barallat J, de Antonio M, Domingo M, Nunez J, et al. Bio-profiling and bio-prognostication of chronic heart failure with mid-range ejection fraction. Int J Cardiol. (2018) 257:188-92. doi: 10.1016/j.ijcard.2018.01.119

16. Savarese G, Orsini N, Hage C, Vedin O, Cosentino F, Rosano G, et al. Utilizing NT-proBNP for eligibility and enrichment in trials in HFpEF, HFmrEF, and HFrEF. JACC Heart Fail. (2018) 6:246-56. doi: 10.1016/j.jchf.2017.12.014

17. Tromp J, Khan M, Mentz RJ, O’Connor CM, Metra M, Dittrich HC, et al. Biomarker profiles of acute heart failure patients with a mid-range ejection fraction. JACC Heart Fail. (2017) 5:507-17. doi: 10.1016/j.jchf.2017.04.007

18. Camici PG, Tschope C, Di Carli MF, Rimoldi O, Van Linthout S. Coronary microvascular dysfunction in hypertrophy and heart failure. Cardiovasc Res. (2020) 116:806-16. doi: 10.1093/cvr/cvaa023

19. Paulus WJ, Tschope C. A novel paradigm for heart failure with preserved ejection fraction: comorbidities drive myocardial dysfunction and remodeling through coronary microvascular endothelial inflammation. J Am Coll Cardiol. (2013) 62:263-71. doi: 10.1016/j.jacc.2013.02.092

20. Amin MN, Mosa AA, El-Shishtawy MM. Clinical study of advanced glycation end products in Egyptian diabetic obese and non-obese patients. Int J Biomed Sci. (2011) 7:191-200.

21. Beyan H, Riese H, Hawa MI, Beretta G, Davidson HW, Hutton JC, et al. Glycotoxin and autoantibodies are additive environmentally determined predictors of type 1 diabetes: a twin and population study. Diabetes. (2012) 61:1192-8. doi: 10.2337/db11-0971

22. Land WG. The role of Damage-Associated Molecular Patterns (DAMPs) in human diseases: part II: DAMPs as diagnostics, prognostics and therapeutics in clinical medicine. Sultan Qaboos Univ Med J. (2015) 15:e157-70.

23. Gladden JD, Linke WA, Redfield MM. Heart failure with preserved ejection fraction. Pflugers Arch. (2014) 466:1037-53. doi: 10.1007/s00424-014-1480-8

24. Simmonds SJ, Cuijpers I, Heymans S, Jones E. Cellular and molecular differences between HFpEF and HFrEF: a step ahead in an improved pathological understanding. Cells-Basel. (2020) 9:242. doi: 10.3390/cells9010242

25. Bezbradica JS, Coll RC, Schroder K. Sterile signals generate weaker and delayed macrophage NLRP3 inflammasome responses relative to microbial signals. Cell Mol Immunol. (2017) 14:118-26. doi: 10.1038/cmi.2016.11

26. Pinto AR, Ilinykh A, Ivey MJ, Kuwabara JT, D’Antoni ML, Debuque R, et al. Revisiting cardiac cellular composition. Circ Res. (2016) 118:400-9. doi: 10.1161/CIRCRESAHA.115.307778

27. Tromp J, Lim SL, Tay WT, Teng TK, Chandramouli C, Ouwerkerk W, et al. Microvascular disease in patients with diabetes with heart failure and reduced ejection versus preserved ejection fraction. Diabetes Care. (2019) 42:1792-9. doi: 10.2337/dc18-2515

28. Franssen C, Chen S, Unger A, Korkmaz HI, De Keulenaer GW, Tschope C, et al. Myocardial microvascular inflammatory endothelial activation in heart failure with preserved ejection fraction. JACC Heart Fail. (2016) 4:312-24. doi: 10.1016/j.jchf.2015.10.007

29. Marti CN, Gheorghiade M, Kalogeropoulos AP, Georgiopoulou VV, Quyyumi AA, Butler J. Endothelial dysfunction, arterial stiffness, and heart failure. J Am Coll Cardiol. (2012) 60:1455-69. doi: 10.1016/j.jacc.2011.11.082

30. Hare JM. Nitroso-redox balance in the cardiovascular system. $N$ Engl J Med. (2004) 351:2112-4. doi: 10.1056/NEJMe048269

31. Karantalis V, Schulman IH, Hare JM. Nitroso-redox imbalance affects cardiac structure and function. J Am Coll Cardiol. (2013) 61:933-5. doi: 10.1016/j.jacc.2012.12.016

32. Shakaryants GAG, Kozhevnikova MV, Kaplunova VY, Ilgisonis IS, Iusupova AO, Zheleznikh EA, et al. Biological markers of endothelial dysfunction in patients with heart failure. Eur J Heart Fail. (2018) 20:433.

33. Fudim M, Ambrosy AP, Sun JL, Anstrom KJ, Bart BA, Butler J, et al. High-sensitivity troponin $\mathrm{i}$ in hospitalized and ambulatory patients with heart failure with preserved ejection fraction: insights from the heart failure clinical research network. J Am Heart Assoc. (2018) 7:e010364. doi: 10.1161/JAHA.118.010364

34. Obokata M, Reddy Y, Melenovsky V, Kane GC, Olson TP, Jarolim P, et al. Myocardial injury and cardiac reserve in patients with heart failure and preserved ejection fraction. J Am Coll Cardiol. (2018) 72:29-40. doi: $10.1016 /$ j.jacc. 2018.04 .039
35. Rouhana S, Farah C, Roy J, Finan A, Rodrigues DAG, Bideaux P, et al. Early calcium handling imbalance in pressure overload-induced heart failure with nearly normal left ventricular ejection fraction. Biochim Biophys Acta Mol Basis Dis. (2019) 1865:230-42. doi: 10.1016/j.bbadis.2018.08.005

36. Westermann D, Kasner M, Steendijk P, Spillmann F, Riad A, Weitmann $\mathrm{K}$, et al. Role of left ventricular stiffness in heart failure with normal ejection fraction. Circulation. (2008) 117:2051-60. doi: 10.1161/CIRCULATIONAHA.107.716886

37. Zile MR, Baicu CF, Gaasch WH. Diastolic heart failure-abnormalities in active relaxation and passive stiffness of the left ventricle. $N$ Engl J Med. (2004) 350:1953-9. doi: 10.1056/NEJMoa032566

38. Schirone L, Forte M, Palmerio S, Yee D, Nocella C, Angelini F, et al. A review of the molecular mechanisms underlying the development and progression of cardiac remodeling. Oxid Med Cell Longev. (2017) 2017:3920195. doi: 10.1155/2017/3920195

39. Triposkiadis F, Butler J, Abboud FM, Armstrong PW, Adamopoulos $\mathrm{S}$, Atherton JJ, et al. The continuous heart failure spectrum: moving beyond an ejection fraction classification. Eur Heart J. (2019) 40:2155-63. doi: 10.1093/eurheartj/ehz158

40. Rommel KP, von Roeder M, Latuscynski K, Oberueck C, Blazek S, Fengler K, et al. Extracellular volume fraction for characterization of patients with heart failure and preserved ejection fraction. J Am Coll Cardiol. (2016) 67:1815-25. doi: 10.1016/j.jacc.2016.02.018

41. Duca F, Kammerlander AA, Zotter-Tufaro C, Aschauer S, Schwaiger ML, Marzluf BA, et al. Interstitial fibrosis, functional status, and outcomes in heart failure with preserved ejection fraction: insights from a prospective cardiac magnetic resonance imaging study. Circ Cardiovasc Imaging. (2016) 9:e005277. doi: 10.1161/CIRCIMAGING.116.005277

42. Doeblin P, Hashemi D, Tanacli R, Lapinskas T, Gebker R, Stehning C, et al. CMR tissue characterization in patients with HFmrEF. J Clin Med. (2019) 8:1877. doi: 10.3390/jcm8111877

43. Lopez B, Gonzalez A, Ravassa S, Beaumont J, Moreno MU, San JG, et al. Circulating biomarkers of myocardial fibrosis: the need for a reappraisal. $J$ Am Coll Cardiol. (2015) 65:2449-56. doi: 10.1016/j.jacc.2015.04.026

44. Lebedev DA, Lyasnikova EA, Vasilyeva EY, Babenko AY, Shlyakhto EV. Type 2 diabetes mellitus and chronic heart failure with midrange and preserved ejection fraction: a focus on serum biomarkers of fibrosis. J Diabetes Res. (2020) 2020:6976153. doi: 10.1155/2020/6976153

45. Weber KT. Cardiac interstitium in health and disease: the fibrillar collagen network. J Am Coll Cardiol. (1989) 13:1637-52. doi: 10.1016/0735-1097(89)90360-4

46. Kasner M, Westermann D, Lopez B, Gaub R, Escher F, Kuhl U, et al. Diastolic tissue doppler indexes correlate with the degree of collagen expression and cross-linking in heart failure and normal ejection fraction. J Am Coll Cardiol. (2011) 57:977-85. doi: 10.1016/j.jacc.2010.10.024

47. Nagueh SF, Shah G, Wu Y, Torre-Amione G, King NM, Lahmers S, et al. Altered titin expression, myocardial stiffness, and left ventricular function in patients with dilated cardiomyopathy. Circulation. (2004) 110:155-62. doi: 10.1161/01.CIR.0000135591.37759.AF

48. Granzier HL, Labeit S. The giant protein titin: a major player in myocardial mechanics, signaling, and disease. Circ Res. (2004) 94:284-95. doi: 10.1161/01.RES.0000117769.88862.F8

49. Hamdani N, Bishu KG, von Frieling-Salewsky M, Redfield MM, Linke WA. Deranged myofilament phosphorylation and function in experimental heart failure with preserved ejection fraction. Cardiovasc Res. (2013) 97:464-71. doi: $10.1093 / \mathrm{cvr} / \mathrm{cvs} 353$

50. Mayourian J, Ceholski DK, Gonzalez DM, Cashman TJ, Sahoo S, Hajjar RJ, et al. Physiologic, pathologic, and therapeutic paracrine modulation of cardiac excitation-contraction coupling. Circ Res. (2018) 122:167-83. doi: 10.1161/CIRCRESAHA.117.311589

51. Bers DM. Cardiac excitation-contraction coupling. Nature. (2002) 415:198205. doi: 10.1038/415198a

52. Miranda-Silva D, Lima T, Rodrigues P, Leite-Moreira A, Falcao-Pires I. Mechanisms underlying the pathophysiology of heart failure with preserved ejection fraction: the tip of the iceberg. Heart Fail Rev. (2021) 26:453-78. doi: 10.1007/s10741-020-10042-0

53. Runte KE, Bell SP, Selby DE, Haussler TN, Ashikaga T, LeWinter $\mathrm{MM}$, et al. Relaxation and the role of calcium in isolated contracting 
myocardium from patients with hypertensive heart disease and heart failure with preserved ejection fraction. Circ Heart Fail. (2017) 10:e004311. doi: 10.1161/CIRCHEARTFAILURE.117.0 04311

54. Pieske B, Maier LS, Piacentino VR, Weisser J, Hasenfuss G, Houser S. Rate dependence of $[\mathrm{Na}+] \mathrm{i}$ and contractility in non-failing and failing human myocardium. Circulation. (2002) 106:447-53. doi: 10.1161/01.CIR.0000023042.50192.F4

55. Cao JL, Adaniya SM, Cypress MW, Suzuki Y, Kusakari Y, Jhun BS, et al. Role of mitochondrial $\mathrm{Ca}(2+)$ homeostasis in cardiac muscles. Arch Biochem Biophys. (2019) 663:276-87. doi: 10.1016/j.abb.2019.01.027

56. Miranda-Silva D, Wust R, Conceicao G, Goncalves-Rodrigues P, Goncalves $\mathrm{N}$, Goncalves A, et al. Disturbed cardiac mitochondrial and cytosolic calcium handling in a metabolic risk-related rat model of heart failure with preserved ejection fraction. Acta Physiol. (2020) 228:e13378. doi: 10.1111/apha.13378

57. Haykowsky MJ, Kitzman DW. Exercise physiology in heart failure and preserved ejection fraction. Heart Fail Clin. (2014) 10:445-52. doi: 10.1016/j.hfc.2014.04.001

58. Kumar AA, Kelly DP, Chirinos JA. Mitochondrial dysfunction in heart failure with preserved ejection fraction. Circulation. (2019) 139:1435-50. doi: 10.1161/CIRCULATIONAHA.118.036259

59. Doenst T, Nguyen TD, Abel ED. Cardiac metabolism in heart failure: implications beyond ATP production. Circ Res. (2013) 113:709-24. doi: 10.1161/CIRCRESAHA.113.300376

60. Liem DA, Nsair A, Setty SP, Cadeiras M, Wang D, Maclellan R, et al. Molecular- and organelle-based predictive paradigm underlying recovery by left ventricular assist device support. Circ Heart Fail. (2014) 7:359-66. doi: 10.1161/CIRCHEARTFAILURE.113.000250

61. Haykowsky MJ, Brubaker PH, John JM, Stewart KP, Morgan TM, Kitzman DW. Determinants of exercise intolerance in elderly heart failure patients with preserved ejection fraction. J Am Coll Cardiol. (2011) 58:265-74. doi: 10.1016/j.jacc.2011.02.055

62. Kitzman DW, Higginbotham MB, Cobb FR, Sheikh KH, Sullivan MJ. Exercise intolerance in patients with heart failure and preserved left ventricular systolic function: failure of the frank-starling mechanism. J Am Coll Cardiol. (1991) 17:1065-72. doi: 10.1016/0735-1097(91)90832-T

63. Borlaug BA, Melenovsky V, Russell SD, Kessler K, Pacak K, Becker LC, et al. Impaired chronotropic and vasodilator reserves limit exercise capacity in patients with heart failure and a preserved ejection fraction. Circulation. (2006) 114:2138-47. doi: 10.1161/CIRCULATIONAHA.106.632745

64. Bhella PS, Prasad A, Heinicke K, Hastings JL, Arbab-Zadeh A, AdamsHuet $B$, et al. Abnormal haemodynamic response to exercise in heart failure with preserved ejection fraction. Eur J Heart Fail. (2011) 13:1296-304. doi: 10.1093/eurjhf/hfr133

65. Pandey A, Parashar A, Kumbhani D, Agarwal S, Garg J, Kitzman D, et al. Exercise training in patients with heart failure and preserved ejection fraction: meta-analysis of randomized control trials. Circ Heart Fail. (2015) 8:33-40. doi: 10.1161/CIRCHEARTFAILURE.114. 001615

66. Haykowsky MJ, Brubaker PH, Stewart KP, Morgan TM, Eggebeen J, Kitzman DW. Effect of endurance training on the determinants of peak exercise oxygen consumption in elderly patients with stable compensated heart failure and preserved ejection fraction. J Am Coll Cardiol. (2012) 60:120-8. doi: 10.1016/j.jacc.2012.02.055

67. Pugliese NR, Fabiani I, Santini C, Rovai I, Pedrinelli R, Natali A, et al. Value of combined cardiopulmonary and echocardiography stress test to characterize the haemodynamic and metabolic responses of patients with heart failure and mid-range ejection fraction. Eur Heart J Cardiovasc Imaging. (2019) 20:828-36. doi: 10.1093/ehjci/jez014

68. Bugger H, Schwarzer M, Chen D, Schrepper A, Amorim PA, Schoepe $\mathrm{M}$, et al. Proteomic remodelling of mitochondrial oxidative pathways in pressure overload-induced heart failure. Cardiovasc Res. (2010) 85:376-84. doi: $10.1093 / \mathrm{cvr} / \mathrm{cvp} 344$

69. Bowen TS, Rolim NP, Fischer T, Baekkerud FH, Medeiros A, Werner $S$, et al. Heart failure with preserved ejection fraction induces molecular, mitochondrial, histological, and functional alterations in rat respiratory and limb skeletal muscle. Eur J Heart Fail. (2015) 17:263-72. doi: 10.1002/ejhf.239
70. Garnier A, Fortin D, Delomenie C, Momken I, Veksler V, Ventura-Clapier R. Depressed mitochondrial transcription factors and oxidative capacity in rat failing cardiac and skeletal muscles. J Physiol. (2003) 551:491-501. doi: 10.1113/jphysiol.2003.045104

71. Rosca MG, Vazquez EJ, Kerner J, Parland W, Chandler MP, Stanley W, et al. Cardiac mitochondria in heart failure: decrease in respirasomes and oxidative phosphorylation. Cardiovasc Res. (2008) 80:30-9. doi: $10.1093 / \mathrm{cvr} / \mathrm{cvn} 184$

72. Sheeran FL, Pepe S. Energy deficiency in the failing heart: linking increased reactive oxygen species and disruption of oxidative phosphorylation rate. Biochim Biophys Acta. (2006) 1757:543-52. doi: 10.1016/j.bbabio.2006.03.008

73. Sorokina N, O'Donnell JM, McKinney RD, Pound KM, Woldegiorgis G, LaNoue KF, et al. Recruitment of compensatory pathways to sustain oxidative flux with reduced carnitine palmitoyltransferase I activity characterizes inefficiency in energy metabolism in hypertrophied hearts. Circulation. (2007) 115:2033-41. doi: 10.1161/CIRCULATIONAHA.106.668665

74. Murray AJ, Cole MA, Lygate CA, Carr CA, Stuckey DJ, Little SE, et al. Increased mitochondrial uncoupling proteins, respiratory uncoupling and decreased efficiency in the chronically infarcted rat heart. J Mol Cell Cardiol. (2008) 44:694-700. doi: 10.1016/j.yjmcc.2008.01.008

75. De Jong KA, Lopaschuk GD. Complex energy metabolic changes in heart failure with preserved ejection fraction and heart failure with reduced ejection fraction. Can J Cardiol. (2017) 33:860-71. doi: 10.1016/j.cjca.2017.03.009

76. Song M, Mihara K, Chen Y, Scorrano L, Dorn GN. Mitochondrial fission and fusion factors reciprocally orchestrate mitophagic culling in mouse hearts and cultured fibroblasts. Cell Metab. (2015) 21:273-86. doi: 10.1016/j.cmet.2014.12.011

77. Stanley WC, Recchia FA, Lopaschuk GD. Myocardial substrate metabolism in the normal and failing heart. Physiol Rev. (2005) 85:1093-129. doi: 10.1152/physrev.00006.2004

78. Fillmore N, Levasseur JL, Fukushima A, Wagg CS, Wang W, Dyck J, et al. Uncoupling of glycolysis from glucose oxidation accompanies the development of heart failure with preserved ejection fraction. Mol Med. (2018) 24:3. doi: 10.1186/s10020-018-0005-x

79. Chen L, Duan Y, Wei H, Ning H, Bi C, Zhao Y, et al. AcetylCoA carboxylase (ACC) as a therapeutic target for metabolic syndrome and recent developments in ACC1/2 inhibitors. Expert Opin Investig Drugs. (2019) 28:917-30. doi: 10.1080/13543784.2019.1 657825

80. Choi YS, de Mattos AB, Shao D, Li T, Nabben M, Kim M, et al. Preservation of myocardial fatty acid oxidation prevents diastolic dysfunction in mice subjected to angiotensin II infusion. J Mol Cell Cardiol. (2016) 100:64-71. doi: 10.1016/j.yjmcc.2016.09.001

81. Puchalska P, Crawford PA. Multi-dimensional roles of ketone bodies in fuel metabolism, signaling, and therapeutics. Cell Metab. (2017) 25:262-84. doi: 10.1016/j.cmet.2016.12.022

82. Karwi QG, Uddin GM, Ho KL, Lopaschuk GD. Loss of metabolic flexibility in the failing heart. Front Cardiovasc Med. (2018) 5:68. doi: $10.3389 / \mathrm{fcvm} .2018 .00068$

83. Bedi KJ, Snyder NW, Brandimarto J, Aziz M, Mesaros C, Worth AJ, et al. Evidence for intramyocardial disruption of lipid metabolism and increased myocardial ketone utilization in advanced human heart failure. Circulation. (2016) 133:706-16. doi: 10.1161/CIRCULATIONAHA.115.0 17545

84. Aubert G, Martin OJ, Horton JL, Lai L, Vega RB, Leone TC, et al. The failing heart relies on ketone bodies as a fuel. Circulation. (2016) 133:698-705. doi: 10.1161/CIRCULATIONAHA.115.017355

85. Maack C, Lehrke M, Backs J, Heinzel FR, Hulot JS, Marx N, et al. Heart failure and diabetes: metabolic alterations and therapeutic interventions: a state-ofthe-art review from the Translational research committee of the heart failure association-European society of cardiology. Eur Heart J. (2018) 39:4243-54. doi: 10.1093/eurheartj/ehy596

86. Deng Y, Xie M, Li Q, Xu X, Ou W, Zhang Y, et al. Targeting mitochondriainflammation circuit by beta-hydroxybutyrate mitigates HFpEF. Circ Res. (2021) 128:232-45. doi: 10.1161/CIRCRESAHA.120.317933 
87. Shiga T, Suzuki A, Haruta S, Mori F, Ota Y, Yagi M, et al. Clinical characteristics of hospitalized heart failure patients with preserved, midrange, and reduced ejection fractions in Japan. ESC Heart Fail. (2019) 6:475-86. doi: 10.1002/ehf2.12418

88. Farre N, Lupon J, Roig E, Gonzalez-Costello J, Vila J, Perez S, et al. Clinical characteristics, one-year change in ejection fraction and long-term outcomes in patients with heart failure with mid-range ejection fraction: a multicentre prospective observational study in Catalonia (Spain). Bmj Open. (2017) 7:e18719. doi: 10.1136/bmjopen-2017-018719

89. Cleland J, Bunting KV, Flather MD, Altman DG, Holmes J, Coats A, et al. Beta-blockers for heart failure with reduced, mid-range, and preserved ejection fraction: an individual patient-level analysis of double-blind randomized trials. Eur Heart J. (2018) 39:26-35. doi: 10.1093/eurheartj/ehx564

90. Wilcox JE, Mann DL. Beta-blockers for the treatment of heart failure with a mid-range ejection fraction: deja-vu all over again? Eur Heart J. (2018) 39:36-8. doi: 10.1093/eurheartj/ehx663

91. Montenegro SF, Carvalho R, Ruivo C, Santos LG, Antunes A, Soares F, et al. Beta-blockers for post-acute coronary syndrome mid-range ejection fraction: a nationwide retrospective study. Eur Heart J Acute Cardiovasc Care. (2019) 8:599-605. doi: 10.1177/2048872619827476

92. Koufou EE, Arfaras-Melainis A, Rawal S, Kalogeropoulos AP. Treatment of heart failure with mid-range ejection fraction: what is the evidence. J Clin Med. (2021) 10:203. doi: 10.3390/jcm10020203

93. Tschope C, Birner C, Bohm M, Bruder O, Frantz S, Luchner A, et al. Heart failure with preserved ejection fraction: current management and future strategies: expert opinion on the behalf of the nucleus of the "heart failure working group" of the German society of cardiology. (DKG). Clin Res Cardiol. (2018) 107:1-19. doi: 10.1007/s00392-017-1170-6

94. McMurray JJ, Adamopoulos S, Anker SD, Auricchio A, Bohm M, Dickstein $\mathrm{K}$, et al. ESC guidelines for the diagnosis and treatment of acute and chronic heart failure 2012: the task force for the diagnosis and treatment of acute and chronic heart failure 2012 of the European society of cardiology. Developed in collaboration with the heart failure association (HFA) of the ESC. Eur Heart J. (2012) 33:1787-847. doi: 10.1093/eurheartj/ehs104

95. Lopatin Y. Heart failure with mid-range ejection fraction and how to treat it. Card Fail Rev. (2018) 4:9-13. doi: 10.15420/cfr.2018:10:1

96. Seferovic PM, Ponikowski P, Anker SD, Bauersachs J, Chioncel O, Cleland J, et al. Clinical practice update on heart failure 2019: pharmacotherapy, procedures, devices and patient management. An expert consensus meeting report of the heart failure association of the European society of cardiology. Eur J Heart Fail. (2019) 21:1169-86. doi: 10.1002/ejhf.1531

97. Koh AS, Tay WT, Teng T, Vedin O, Benson L, Dahlstrom U, et al. A comprehensive population-based characterization of heart failure with mid-range ejection fraction. Eur J Heart Fail. (2017) 19:1624-34. doi: 10.1002/ejhf.945

98. Yip GW, Wang M, Wang T, Chan S, Fung JW, Yeung L, et al. The Hong Kong diastolic heart failure study: a randomised controlled trial of diuretics, irbesartan and ramipril on quality of life, exercise capacity, left ventricular global and regional function in heart failure with a normal ejection fraction. Heart. (2008) 94:573-80. doi: 10.1136/hrt.2007.117978

99. Massie BM, Carson PE, McMurray JJ, Komajda M, McKelvie R, Zile MR, et al. Irbesartan in patients with heart failure and preserved ejection fraction. N Engl J Med. (2008) 359:2456-67. doi: 10.1056/NEJMoa0805450

100. Xiang Y, Shi W, Li Z, Yang Y, Wang SY, Xiang R, et al. Efficacy and safety of spironolactone in the heart failure with mid-range ejection fraction and heart failure with preserved ejection fraction: a meta-analysis of randomized clinical trials. Medicine. (2019) 98:e14967. doi: 10.1097/MD.0000000000014967

101. Solomon SD, Claggett B, Lewis EF, Desai A, Anand I, Sweitzer NK, et al. Influence of ejection fraction on outcomes and efficacy of spironolactone in patients with heart failure with preserved ejection fraction. Eur Heart J. (2016) 37:455-62. doi: 10.1093/eurheartj/ehv464

102. Enzan N, Matsushima S, Ide T, Kaku H, Higo T, Tsuchihashi-Makaya M, et al. Spironolactone use is associated with improved outcomes in heart failure with mid-range ejection fraction. ESC Heart Fail. (2020) 7:339-47. doi: $10.1002 /$ ehf2.12571
103. Xin YG, Chen X, Zhao YN, Hu J, Sun Y, Hu WY. Outcomes of spironolactone treatment in patients in Northeast China suffering from heart failure with mid-range ejection fraction. Curr Med Res Opin. (2019) 35:561-8. doi: 10.1080/03007995.2018.1520695

104. Selvaraj S, Claggett B, Shah SJ, Anand IS, Rouleau JL, Desai AS, et al. Utility of the cardiovascular physical examination and impact of spironolactone in heart failure with preserved ejection fraction. Circ Heart Fail. (2019) 12:e6125. doi: 10.1161/CIRCHEARTFAILURE.119.006125

105. McMurray JJ, Packer M, Desai AS, Gong J, Lefkowitz MP, Rizkala AR, et al. Angiotensin-neprilysin inhibition versus enalapril in heart failure. N Engl J Med. (2014) 371:993-1004. doi: 10.1056/NEJMoa1409077

106. Solomon SD, McMurray J, Anand IS, Ge J, Lam C, Maggioni AP, et al. Angiotensin-neprilysin inhibition in heart failure with preserved ejection fraction. N Engl J Med. (2019) 381:1609-20. doi: 10.1056/NEJMoa1908655

107. Nie D, Xiong B, Qian J, Rong S, Yao Y, Huang J. The effect of sacubitril-valsartan in heart failure patients with mid-range and preserved ejection fraction: a meta-analysis. Heart Lung Circ. (2020) 30:683-91. doi: $10.1016 /$ j.hlc.2020.10.012

108. Long-Term Intervention with Pravastatin in Ischaemic Disease (LIPID) Study Group. Prevention of cardiovascular events and death with pravastatin in patients with coronary heart disease and a broad range of initial cholesterol levels. N Engl J Med. (1998) 339:1349-57. doi: 10.1056/NEJM199811053391902

109. Sacks FM, Pfeffer MA, Moye LA, Rouleau JL, Rutherford JD, Cole TG, et al. The effect of pravastatin on coronary events after myocardial infarction in patients with average cholesterol levels. Cholesterol and recurrent events trial investigators. N Engl J Med. (1996) 335:1001-9. doi: 10.1056/NEJM199610033351401

110. Heart Protection Study Collaborative Group. MRC/BHF heart protection study of cholesterol lowering with simvastatin in 20,536 high-risk individuals: a randomised placebo-controlled trial. Lancet. (2002) 360:7-22. doi: 10.1016/S0140-6736(02)09327-3

111. Alehagen U, Benson L, Edner M, Dahlstrom U, Lund LH. Association Between use of statins and mortality in patients with heart failure and ejection fraction of $\geq 50$. Circ Heart Fail. (2015) 8:862-70. doi: 10.1161/CIRCHEARTFAILURE.115.002143

112. Baartscheer A, Schumacher CA, Wust RC, Fiolet JW, Stienen GJ, Coronel $\mathrm{R}$, et al. Empagliflozin decreases myocardial cytoplasmic $\mathrm{Na}(+)$ through inhibition of the cardiac $\mathrm{Na}(+) / \mathrm{H}(+)$ exchanger in rats and rabbits. Diabetologia. (2017) 60:568-73. doi: 10.1007/s00125-016-4134-x

113. Striepe K, Jumar A, Ott C, Karg MV, Schneider MP, Kannenkeril D, et al. Effects of the selective sodium-glucose cotransporter 2 inhibitor empagliflozin on vascular function and central hemodynamics in patients with type 2 diabetes mellitus. Circulation. (2017) 136:1167-9. doi: 10.1161/CIRCULATIONAHA.117.029529

114. Kang S, Verma S, Hassanabad AF, Teng G, Belke DD, Dundas JA, et al. Direct effects of empagliflozin on extracellular matrix remodelling in human cardiac myofibroblasts: novel translational clues to explain EMPA-REG OUTCOME results. Can J Cardiol. (2020) 36:543-53. doi: 10.1016/j.cjca.2019.08.033

115. Soga F, Tanaka H, Tatsumi K, Mochizuki Y, Sano H, Toki H, et al. Impact of dapagliflozin on left ventricular diastolic function of patients with type 2 diabetic mellitus with chronic heart failure. Cardiovasc Diabetol. (2018) 17:132. doi: 10.1186/s12933-018-0775-Z

116. Zinman B, Wanner C, Lachin JM, Fitchett D, Bluhmki E, Hantel S, et al. Empagliflozin, cardiovascular outcomes, and mortality in type 2 diabetes. $N$ Engl J Med. (2015) 373:2117-28. doi: 10.1056/NEJMoa1504720

117. Kato ET, Silverman MG, Mosenzon O, Zelniker TA, Cahn A, Furtado R, et al. Effect of dapagliflozin on heart failure and mortality in type 2 diabetes mellitus. Circulation. (2019) 139:2528-36. doi: 10.1161/CIRCULATIONAHA.119.040130

118. Connelly KA, Zhang Y, Visram A, Advani A, Batchu SN, Desjardins JF, et al. Empagliflozin improves diastolic function in a nondiabetic rodent model of heart failure with preserved ejection fraction. JACC Basic Transl Sci. (2019) 4:27-37. doi: 10.1016/j.jacbts.2018.11.010

119. Withaar C, Meems L, Markousis-Mavrogenis G, Boogerd CJ, Sillje H, Schouten EM, et al. The effects of liraglutide and dapagliflozin on cardiac function and structure in a multi-hit mouse model of heart failure 
with preserved ejection fraction. Cardiovasc Res. (2020). 117:2108-24. doi: $10.1093 / \mathrm{cvr} / \mathrm{cvaa} 256$

120. Kimura T, Nakamura K, Miyoshi T, Yoshida M, Akazawa K, Saito Y, et al. Inhibitory effects of tofogliflozin on cardiac hypertrophy in dahl salt-sensitive and salt-resistant rats fed a high-fat diet. Int Heart J. (2019) 60:728-35. doi: 10.1536/ihj.18-392

121. Tschope C, Van Linthout S. New insights in (inter)cellular mechanisms by heart failure with preserved ejection fraction. Curr Heart Fail Rep. (2014) 11:436-44. doi: 10.1007/s11897-014-0219-3

122. Stasch JP, Pacher P, Evgenov OV. Soluble guanylate cyclase as an emerging therapeutic target in cardiopulmonary disease. Circulation. (2011) 123:226373. doi: 10.1161/CIRCULATIONAHA.110.981738

123. Pieske B, Maggioni AP, Lam C, Pieske-Kraigher E, Filippatos G, Butler J, et al. Vericiguat in patients with worsening chronic heart failure and preserved ejection fraction: results of the SOluble guanylate Cyclase stimulatoR in heArT failurE patientS with PRESERVED EF (SOCRATES-PRESERVED) study. Eur Heart J. (2017) 38:1119-27. doi: 10.1093/eurheartj/ehw593

124. Armstrong PW, Lam C, Anstrom KJ, Ezekowitz J, Hernandez AF, O'Connor CM, et al. Effect of vericiguat vs placebo on quality of life in patients with heart failure and preserved ejection fraction: the VITALITY-HFpEF randomized clinical trial. JAMA. (2020) 324:1512-21. doi: 10.1001/jama.2020.15922

125. Armstrong PW, Pieske B, Anstrom KJ, Ezekowitz J, Hernandez AF, Butler J, et al. Vericiguat in patients with heart failure and reduced ejection fraction. N Engl J Med. (2020) 382:1883-93. doi: 10.1056/NEJMoa1915928

126. Emdin M, Aimo A, Castiglione V, Vergaro G, Georgiopoulos G, Saccaro LF, et al. Targeting cyclic guanosine monophosphate to treat heart failure: JACC review topic of the week. J Am Coll Cardiol. (2020) 76:1795-807. doi: 10.1016/j.jacc.2020.08.031

127. Kleemann T. Cardiac contractility modulation. A new form of therapy for patients with heart failure and narrow QRS complex? Herz. (2015) 40:945-51. doi: 10.1007/s00059-015-4362-8

128. Muller D, Remppis A, Schauerte P, Schmidt-Schweda S, Burkhoff D, Rousso $\mathrm{B}$, et al. Clinical effects of long-term cardiac contractility modulation (CCM) in subjects with heart failure caused by left ventricular systolic dysfunction. Clin Res Cardiol. (2017) 106:893-904. doi: 10.1007/s00392-017-1135-9
129. Yu CM, Chan JY, Zhang Q, Yip GW, Lam YY, Chan A, et al. Impact of cardiac contractility modulation on left ventricular global and regional function and remodeling. JACC Cardiovasc Imaging. (2009) 2:1341-9. doi: 10.1016/j.jcmg.2009.07.011

130. Abraham WT, Kuck KH, Goldsmith RL, Lindenfeld J, Reddy VY, Carson $\mathrm{PE}$, et al. A randomized controlled trial to evaluate the safety and efficacy of cardiac contractility modulation. JACC Heart Fail. (2018) 6:874-83. doi: 10.1016/j.jchf.2018.04.010

131. Tschope C, Kherad B, Klein O, Lipp A, Blaschke F, Gutterman D, et al. Cardiac contractility modulation: mechanisms of action in heart failure with reduced ejection fraction and beyond. Eur J Heart Fail. (2019) 21:14-22. doi: 10.1002/ejhf.1349

132. Tschope C, Van Linthout S, Spillmann F, Klein O, Biewener S, Remppis A, et al. Cardiac contractility modulation signals improve exercise intolerance and maladaptive regulation of cardiac key proteins for systolic and diastolic function in HFpEF. Int J Cardiol. (2016) 203:1061-6. doi: 10.1016/j.ijcard.2015.10.208

Conflict of Interest: The authors declare that the research was conducted in the absence of any commercial or financial relationships that could be construed as a potential conflict of interest.

Publisher's Note: All claims expressed in this article are solely those of the authors and do not necessarily represent those of their affiliated organizations, or those of the publisher, the editors and the reviewers. Any product that may be evaluated in this article, or claim that may be made by its manufacturer, is not guaranteed or endorsed by the publisher.

Copyright $\odot 2021 \mathrm{Li}$, Zhao, Zhang, Ning, Tu, Xu and Zeng. This is an open-access article distributed under the terms of the Creative Commons Attribution License (CC $B Y)$. The use, distribution or reproduction in other forums is permitted, provided the original author(s) and the copyright owner(s) are credited and that the original publication in this journal is cited, in accordance with accepted academic practice. No use, distribution or reproduction is permitted which does not comply with these terms. 